\title{
DOES INITIAL APPROPRIATION CREATE NEW OBLIGATIONS?
}

\author{
Jesse Spafford
}

\begin{abstract}
Signature Claim of entitlement theories of justice is that people have private property rights over objects. Additionally, proponents of these theories generally maintain that these rights can be established unilaterally: by performing the right kind of appropriative act, an individual can convert unowned natural resources into private property without having to obtain the consent of others. However, many philosophers have objected to this latter claim as follows:
\end{abstract}

1. Morally equal people do not have the power to unilaterally impose obligations on one another (i.e., impose such obligations without consent).

2. The power to unilaterally appropriate is a power to unilaterally impose obligations on others, as they are now obligated to refrain from using the appropriated thing.

3. Thus, people lack the power to unilaterally appropriate.

This moral equality argument — or some variant thereof_- has been advanced by a number of philosophers, typically as part of a broader account of the conditions under which such appropriation would be possible. ${ }^{1}$ However, a recent argument advanced by Bas van der Vossen threatens the second premise, as it raises the possibility that initial appropriation does not create new obligations for others, but rather alters the requirements implied by their already existing obligations in a way that is unproblematic vis-à-vis moral equality. ${ }^{2}$ This paper

1 Bas van der Vossen helpfully catalogs a number of such proponents-primarily Kantiansincluding Gibbard ("Natural Property Rights"), Ripstein (Force and Freedom, 272), and Waldron (“The Right to Private Property," 265-67, 280, and "Kant's Legal Positivism," 1557). He also identifies the many philosophers who have read Kant as making this argument, including Flikschuh (Kant and Modern Political Philosophy, 136, 141, 228) and Stilz (Liberal Loyalty, 45, 55). A similar argument is made by Wenar, though he does not lean as heavily on the moral equality premise ("Against Moral Responsibility," 806-7).

2 Van der Vossen, "Imposing Duties and Original Appropriation." 
attempts to rescue the moral equality argument from van der Vossen's objection by showing that acts of initial appropriation do, in fact, imply a morally problematic power to impose duties on others. ${ }^{3}$

\section{THE DUTY ALTERATION OBJECTION}

To begin, it will be helpful to introduce the normative ontology that van der Vossen employs when objecting to the second premise. Specifically, he draws a distinction between obligations and their associated requirements, where the former are expressed by general normative propositions-e.g., " $Q$ is obligated not to touch $P$ 's body without $P$ 's permission" - while the latter are expressed by action-specific normative propositions whose truth values are a function of both certain obligations and certain facts about the world. For example, if (a) $Q$ has an obligation not to touch P's body and (b) $P$ has hair, then $Q$ has the requirement that she not touch $P$ 's hair.

Given that requirements are a function of both obligations and empirical facts, it follows that there are two ways that one might modify those requirements, namely, by changing some normative fact(s) about which obligations obtain or by changing the relevant empirical facts. ${ }^{4}$ What van der Vossen calls $d u$ ty-creation, then, is the Hohfeldian power to change some person's requirements by generating new obligations for her (or, perhaps, by changing the content of her existing obligations); by contrast, duty-alteration is the power to change requirements by changing relevant empirical facts. ${ }^{5}$ Thus, when $P$ grows out her hair, she is exercising her power of duty-alteration rather than duty-creation, as she changes Q's requirements without changing Q's obligations.

With this distinction in place, premise 1 of the argument from moral equality - which denies that people have the power to impose obligations on one another-can now be understood as a denial that people have the power of duty-creation. And van der Vossen is happy to concede this point, as his view is that no one has such a power. However, this view also leads him to reject arguments that cite the unacceptability of duty-creation as the reason that a particular mor-

3 The paper will also function as a reply to related defenses of initial appropriation, including those made by Gaus and Lomasky ("Are Property Rights Problematic?") and Simmons (“Original-Acquisition Justifications of Private Property").

4 Van der Vossen, "Imposing Duties and Original Appropriation," 69.

5 Van der Vossen, "Imposing Duties and Original Appropriation," 70. Technically, van der Vossen says the particular acts are instances of either duty-creation or duty-alteration (as opposed to the power to carry out such acts as just asserted). However, using the terms to refer to powers helps to clarify the discussion, with the slight misattribution then being necessary for introducing the term as it is to be used later in the text. 
al power does not obtain. Indeed, while many have objected to initial appropriation on the grounds that such appropriation imposes new obligations upon others, van der Vossen argues that initial appropriation is merely an exercise of the power of duty-alteration, as he posits that people have the following natural conditional right to appropriate:

For all persons $P$ and $Q$ at times $t_{1}$ and $t_{2}, P$ has a right against $Q$ that $[Q$ respect $P$ as the rightful owner of $O$ at $t_{2}$ on the condition that $P$ performs appropriative act $A$ on object $O$ under conditions $C$ at $\left.t_{1}\right]$. $^{6}$

The right that $P$ has in this case is that the bracketed conditional obtains-with $Q$ then having a correlative obligation to make the bracketed conditional obtain. More specifically, this obligation entails that $Q$ act in the way specified by the consequent (respect $P$ as the rightful owner) when the antecedent obtains ( $P$ performs $A$ on $O$ ). Then, just as $P$ growing out her hair changes some of the requirements of $Q$ 's obligation not to touch $P$ - but does so without adding to or modifying $Q$ 's existing obligations $-P$ doing $A$ changes the requirements of $Q$ 's natural conditional obligation via the alteration of an empirical fact.

Given that $P$ 's appropriation merely changes $Q$ 's requirements, the act would not entail the prohibited power to impose obligations. In other words, there are two sorts of moral powers, one problematic (duty-creation), one unproblematic (duty-alteration), with both hair growing and initial appropriation implying only the latter. Thus, to rescue the moral equality argument, one must show that there is some other principled basis for demarcating hair growing from initial appropriation such that it can be maintained that the latter is uniquely problematic. It is this task that the paper will take up in the next section.

\section{THE REVISED MORAL EQUALITY ARGUMENT}

The central contention of the duty-alteration objection is that, while both hair growing and initial appropriation change others' requirements, neither imposes new obligations. However, this section will argue that, in fact, the $P$ who grows out her hair changes neither Q's obligations nor Q's requirements. By contrast, the $P$ who appropriates some unowned thing does change Q's requirements. Thus, the moral equality argument can sidestep the duty-alteration objection by maintaining that it is the power to unilaterally impose new requirements that runs contrary to the assumption of human moral equality.

To begin, note that a foundational assumption of the duty-alteration objec-

6 Van der Vossen, "Imposing Duties and Original Appropriation," 74. While brackets appear in the cited text, some variables have been replaced for stylistic consistency. 
tion is that if $P$ grows out her hair, then $Q$ has a new requirement not to touch $P$ 's hair. But why think, as van der Vossen does, that $Q$ lacked this requirement when $P$ lacked hair? This crucial premise would seem to rest on the following tacit argument:

1. $P$ does not have hair.

2. If $P$ does not have hair, then $Q$ cannot touch $P$ 's hair.

3. $Q$ is required to $\phi$ only if she can $\phi$ (oIC: "ought" implies "can").

4. Thus, when $P$ has no hair, it is false that $Q$ is required not to touch $P$ 's hair (i.e., there is no requirement that $Q$ not touch $P$ 's hair).

The problem with this argument, of course, is that it is invalid. To see this, note that OIC together with the proposition that $Q$ cannot touch $P$ 's hair implies that it is not required that $Q$ touch $P$ 's hair-not the asserted conclusion that $Q$ is not forbidden from touching $P$ 's hair (where $Q$ is forbidden from $\phi$-ing just in case she is required not to $\phi$ ). To reach this conclusion via oIc, it would have to be the case that $Q$ is unable to avoid touching P's hair; however, in the stipulated case where $P$ lacks hair, $Q$ is fully able to avoid touching $P$ 's hair. Thus, the conclusion that $P$ is not forbidden from touching $P$ 's (nonexistent) hair does not follow from the argument's premises.

Given the failure of this argument, the proponent of the moral equality argument could insist that, just as $Q$ is forbidden from touching $P$ 's hair when $P$ has hair, $Q$ is equally forbidden from touching $P$ 's (nonexistent) hair when $P$ does not have hair-and, thus, that $P$ does not impose any new requirement on $Q$ by growing her hair. By contrast, the $P$ who appropriates some object $O$ does impose new requirements upon $Q$ as $Q$ was free to use $O$ prior to its appropriation but becomes forbidden from such use as soon as $P$ appropriates $O$. Thus, there is an important difference between hair growing and initial appropriation: the latter imposes novel requirements on others while the former does not.

This difference, in turn, allows for a restatement of the moral equality argument where what is proscribed is not the power to unilaterally impose novel obligations but, rather, the power to unilaterally impose novel requirements. While there is no contradiction in morally equal people having the power to unilaterally grow out their hair, there is a contradiction between people being moral equals and their having the power to unilaterally impose novel requirements on one another-or at least so the proponent of the moral equality argument might maintain. Thus, she would be able to sidestep the duty-alteration objection, as she can insist that, contra van der Vossen's claim, there is an important moral difference between initial appropriation and pedestrian activities like hair growing, even while conceding his contention that neither imposes novel obligations. 


\section{THE "OUght NOT" IMPlies "CAN" OBJECTION}

In response to this proposal, three objections might be raised. First, it might be objected that there is an easy fix for the invalid argument presented in the previous section: simply replace premise 3 ( $Q$ is required to $\phi$ only if she can $\phi$ ) with the premise that $Q$ is forbidden from $\phi$-ing only if she can $\phi$. Given this premise, $Q$ would not be forbidden from touching $P$ 's hair when $P$ has no hair, with this action only becoming forbidden when $P$ grows out her hair. Thus, hair growing would impose novel requirements on others, collapsing the proposed distinction between hair growing and appropriation.

However, while this replacement would render the argument valid, such a move would come at the expense of the plausibility of the third premise. Note that OIC is already controversial, with many arguments having been raised against it. ${ }^{7}$ However, even if one concedes that "ought" implies "can," there is little reason for thinking that "ought not" implies "can" (ONIC) as the amended premise 3 contends. Indeed, a quick survey of the prominent arguments for OIC reveals that none of the posited reasons for endorsing oIC can be appealed to in support of oNIC. ${ }^{8}$ For example, David Copp argues that a moral theory that required a person to $\phi$ when she cannot $\phi$ would be unfair-but moral theories cannot be unfair in this way. ${ }^{9}$ Thus, he concludes that one is required to $\phi$ only if one can $\phi$. However, even if one grants this argument, there is nothing seemingly unfair about a moral theory that forbids a person from doing something she cannot do. Given the absence of such unfairness, it would then follow that Copp's argument for OIC cannot be repurposed to support ONIC.

Another popular line of argument for OIC is that this principle is needed to explain a number of facts about moral reasoning. For example, Frances Howard-Snyder argues that, if oIC were false, then we could not adequately explain (a) why an agent who cannot $\phi$ (where she otherwise ought to $\phi$ ) ought to do the "second-best" thing instead, (b) why an agent who ought to $\phi$ also ought to $\psi$ when $\psi$-ing is a necessary condition of her $\phi$-ing, and (c) why there are prima

7 For some prominent arguments against this premise see Sinnott-Armstrong, "'Ought' Conversationally Implies 'Can”"; Saka, "Ought Does Not Imply Can”; Ryan, "Doxastic Compatibilism and the Ethics of Belief”; Graham, "'Ought' and Ability”; Waller, "Against Moral Responsibility," 179-89; and Talbot, “The Best Argument for 'Ought Implies Can' Is a Better Argument against 'Ought Implies Can.”

8 These arguments all use slightly different moral language, with some being concerned with "ought" while others are concerned with obligations (typically "all things considered," ultima facie obligations). However, these generally seem to correspond to the way "requirement" is being used in this paper.

9 Copp, “'Ought' Implies 'Can,' Blameworthiness, and the Principle of Alternate Possibilities.” 
facie obligations that are overridden by other obligations (as opposed to the agent simply having both obligations simultaneously). ${ }^{10}$ In each case, Howard-Snyder contends that the best explanation is that an agent only ought to $\phi$ if she can $\phi$. However, again, one can fully concede this point while still denying ONIC: even if it is true that OIC must be true to explain (a), (b), and (c), ONIC does not appear to do any important explanatory work. Thus, this argument for OIC also cannot be generalized to defend onic.

Finally, there is a popular strategy for defending oIC that appeals to reasons for actions. For example, Peter Vranas argues that (1) an agent has an obligation to $\phi$ only if she has reason to $\phi$, (2) she has reason to $\phi$ only if $\phi$-ing is a potential option for her, and (3) $\phi$-ing is a potential option for her only if she can $\phi$; thus, she has an obligation to $\phi$ only if she can $\phi .{ }^{11}$ Similarly, Bart Streumer argues that there cannot be a reason for an agent to $\phi$ if she lacks the ability to $\phi$, and thus, she cannot have the most reason to $\phi$ if she is unable to $\phi .{ }^{12} \mathrm{He}$ contends that this latter claim has the same truth conditions as the claim that it cannot be the case that a person ought to $\phi$ when she is unable to $\phi$ (i.e., oIC); thus, oIC is true.

Again, it does not appear that this argument can be repurposed to support ONIC. While it may be true that one must be able to $\phi$ if one is to have a reason to $\phi$-with reason to $\phi$ being a necessary condition of being required to $\phi$-it is not obvious that one must be able to $\phi$ to have reason not to $\phi$. To see this, consider some of the supporting arguments Streumer gives for thinking that one must be able to $\phi$ if one is to have reason to $\phi$. First, he argues that if one could have reason to $\phi$ without having the ability to $\phi$, one could have "crazy" reasons like a reason to jump thirty-thousand feet into the air to stop a plane from crashing. ${ }^{13}$ However, given that it is absurd to think we have such reasons, he contends that reasons are ability constrained. However, being forbidden from doing things one cannot do generates no such "crazy" reasons, as there seems to be nothing "crazy" about having reason not to jump thirty-thousand feet into the air, for example.

Alternatively, Streumer argues that if agents can have reasons to do things they cannot do (i.e., oIC is false), then it will turn out that they will have most reason to do what they cannot (e.g., go back in time and stop all the wars). ${ }^{14}$ Thus, they will have to try to spend their lives pointlessly trying to do the impossible-an absurd conclusion that requires the rejection of the premise that

10 Howard-Snyder, "'Cannot' Implies 'Not Ought," 236-41.

11 Vranas, "I Ought, Therefore I Can,” 171-72.

12 Streumer, "Reasons and Impossibility," 351-58.

13 Streumer, "Reasons and Impossibility," 358-59.

14 Streumer, "Reasons and Impossibility," 365. 
OIC is false. ${ }^{15}$ Again, though, this argument cannot be repurposed to establish ONIC, as being forbidden from carrying out undoable actions will not demand any sort of pointless efforts on the part of agents. Thus, arguments for oIC that appeal to the relationship between ability and reasons cannot be employed to defend onIC.

There is one argument for oIC that can be repurposed to defend onIC. This argument contends that the point of moral evaluation of actions is to aid in deliberation; however, given that undoable actions are not objects of deliberation, it is inappropriate to assign the moral predicate of "required" to such actions. ${ }^{16}$ Thus, one is only required to do actions that one can do (i.e., oIc) — a conclusion that can be generalized to defend ONIC if one insists that it is inappropriate to assign any moral predicates to actions that are not the objects of deliberation (i.e., undoable actions can be neither required nor forbidden).

The problem with this argument is its contention that moral predicates can only be applied to those actions that factor into deliberation. Suppose that some agent is a pacifist such that she would not even consider harming another person. For such a person, the possible action of killing her friend would never enter into her deliberation process. Thus, if one takes moral predication to be constrained by deliberation, it would then follow that the pacifist is not required to refrain from murdering her friend. However, this would seem to be a reductio of the premise that moral predicates only apply to those actions that factor into deliberations. ${ }^{17}$ Given that this reductio undermines the only apparent argument for ONIC, there would seem to be no basis for rejecting the revised moral equality argument's contention that $Q$ is forbidden from touching $P$ 's hair even when $P$ lacks hair.

\section{THE OCCUPATION OBJECTION}

There is a second possible objection that, like the first, contends that both initial appropriation and hair growing impose new requirements. Suppose that $P$ grows out her hair such that it comes to occupy space $S$ at time $T$. This objec-

15 Streumer, "Reasons and Impossibility," 365. Streumer also has an additional argument, but I think it ultimately collapses into the argument from crazy reasons, though I will not argue for that here.

16 Copp makes a point along these lines (“'Ought' Implies 'Can,' Blameworthiness, and the Principle of Alternate Possibilities," 273-74).

17 Peter Graham makes a related point when arguing that we need not posit that "ought implies can" when explaining our process of deliberation. He notes that we not only exclude undoable actions at the outset of our deliberation, but also actions we have no intention of doing (“'Ought' and Ability," 371-72). 
tion argues that it would now be true that $Q$ is required not to move her hand through $S$ at $T$-something that was not true before $P$ grew out her hair. Thus, contra the argument of section 3 , hair growing does result in requirement change.

In response to this objection, recall that moral requirements are specific to particular actions-i.e., the propositions that express such requirements will refer to some particular action and attach a moral predicate (e.g., "required" or "forbidden") to a description of that action. Further, note that actions are spatio-temporal entities that include particular bits of matter moving through particular spaces at particular times. Thus, actions are properly individuated on the basis of the physical parts that compose them. For example, consider the case of $P$ walking through an unoccupied doorway versus $P$ passing through that same doorway but trampling $Q$ in the process. Even though both might fall under the description of " $P$ moves through the doorway," these actions are properly understood as distinct because (a) P's physical motion will differ across the two cases (in one she shoves $Q$ as part of her movement) and (b) one action includes $Q$ while the other does not.

Given that requirements are specific to particular actions, it becomes clear that the occupation objection is wrong to claim that the action of $Q$ moving her hand through $S$ at $T$ becomes newly forbidden when P's hair comes to occupy $S$. Indeed, this claim only seems true because the hand-moving action is under-described. If one specifies that the action in question is $Q$ moving her hand through $S$ and brushing $P$ 's hair in the process, then the action would still be forbidden even before $P$ grows out her hair. By contrast, if the action in question is $Q$ moving her hand through unoccupied space $S$, then the action would not be forbidden before or after $P$ grows out her hair. Rather, it would merely become impossible for $Q$ to do this action without the deontic status of the action changing. Thus, the occupation objection rests on a false premise and the revised moral equality argument can be sustained. ${ }^{18}$

\section{THE ETERNALISM OBJECTION}

While the first two objections maintained that both hair growing and initial appropriation impose new requirements on others, the third objection contends that neither action imposes such requirements. Specifically this objection holds

18 Another way of putting this point is that, even if the proposition " $Q$ is forbidden from moving her hand through $S$ at $T$ ” changes truth values when $P$ grows out her hair, this proposition does not express a requirement because it is not specific to a particular action. For a new requirement to be imposed, some proposition that expresses a requirement must change from false to true - a change that appropriation brings about but hair growing does not. 
that a novel requirement is imposed just in case the truth value of the proposition that expresses that requirement changes from false to true. However, there is a popular metaphysical view that denies that propositions can have different truth values at different times. Thus, the distinction between initial appropriation and hair growing cannot be stated in terms of requirement change, as requirements cannot change across time.

This objection assumes the popular position that propositions are eternal in the sense that their truth value does not change over time, thanks in part to the fact that their content is temporally indexed. ${ }^{19}$ For example, when a person in Chicago says, "It is raining" at 12:45 PM on December 20, 1989, she is really expressing the proposition that it is raining in Chicago at 12:45 PM on December 20, 1989. Further, the eternalist claims that this proposition is true both at the time the sentence is uttered and thirty years later when the speaker is in New York and the weather is clear both there and in Chicago. Thus, in contrast to temporalist views, which hold that the sentence "It is raining" expresses a proposition that is true when it is raining and false when it is not-i.e., a proposition that changes truth values across time-the eternalist position holds that propositions are timelessly true (or timelessly false).

Given an eternalist view of propositions, it would then follow that the truth values of requirement-expressing propositions do not change across time-i.e., no new requirements could be imposed. To see this, consider the case of an object $O$ that is unowned at $t_{1}$ but is appropriated by $P$ at $t_{2}$ and then owned by $P$ at time $t_{3}$. Given the general obligation not to touch others' property without their consent coupled with the empirical fact that $P$ carried out an appropriative act at $t_{2}$, the following proposition would be true: $Q$ is required not to touch $O$ at $t_{3}$. However, if this proposition is true, then, on the eternalist view, it is equally true at $t_{1}$ when $O$ is unowned as it is at $t_{3}$ when $P$ has come to own it. Thus, contra the revised moral equality argument, $P$ 's appropriative act does not generate a new requirement that $Q$ not touch $O$ at $t_{3}$.

The most straightforward reply to this objection is to simply concede the point and restate the revised moral equality argument in terms that are compatible with eternalism. This twice-revised argument would avoid talk of requirement change and, instead, put things in terms of the counterfactual requirement differences associated with initial appropriation versus hair growing. Specifically, note that when $P$ appropriates object $O, Q$ ends up with a requirement that she would not have had if $P$ had not appropriated $O$, namely, the requirement not to touch $O$. By contrast, $Q$ is equally required not to touch $P$ 's hair in the world

19 While this is the dominant view, there are dissenters, including Prior, "Thank Goodness That's Over"; and Brogaard, Transient Truths. 
where $P$ grows out her hair and in the world in which she keeps her head shaved. Indeed, the arguments above have sought to demonstrate that $P$ 's lack of hair does nothing to negate the proposition that $Q$ is forbidden from touching $P$ 's hair. Thus, even granting the eternalist claim about propositions, there is still an important difference between hair growing and initial appropriation: the latter generates a counterfactual requirement difference while the former does not. It is this power-the power to unilaterally burden people with requirements they would not have otherwise had-that is incompatible with moral equality. Or so the proponent of the moral equality argument could maintain in the face of the duty-alteration and eternalism objections.

\section{CONCLUSION}

This paper has attempted to rescue the moral equality argument from the objection that the power to appropriate is no different from the power to grow out one's hair. Specifically, it has attempted to demonstrate that only initial appropriation imposes new requirements on others, making the power to unilaterally appropriate morally problematic in a way that the unilateral power to grow out one's hair is not. Finally, the paper rejected three additional reasons for thinking that initial appropriation and hair growing are of a kind (e.g., because both/ neither impose new requirements on others). Thus, it concludes that the moral equality argument survives the duty-alteration objection. ${ }^{20}$

The Graduate Center, CUNY jesse.e.spafford@gmail.com

REFERENCES

Brogaard, Berit. Transient Truths: An Essay in the Metaphysics of Propositions. Oxford: Oxford University Press, 2012.

Copp, David. “'Ought' Implies 'Can,' Blameworthiness, and the Principle of Alternate Possibilities.” In Moral Responsibility and Alternative Possibilities: Essays on the Importance of Alternative Possibilities, edited by David Widerker and Michael McKenna. Burlington, vT: Ashgate Press, 2003. his many helpful comments on earlier drafts of this paper. I am also grateful to the American Council of Learned Societies for providing me with a Mellon/ACLS Dissertation Completion Fellowship that helped make this research possible. 
Flikschuh, Katrin. Kant and Modern Political Philosophy. Cambridge: Cambridge University Press, 2000.

Gaus, Gerald F., and Loren E. Lomasky. "Are Property Rights Problematic?” The Monist 73, no. 4 (October 1990): 483-503.

Gibbard, Alan. "Natural Property Rights." Noûs 10, no. 1 (March 1976): 77-86.

Graham, Peter. "'Ought' and Ability." Philosophical Review 120, no. 3 (July 2011): $337-82$.

Howard-Snyder, Frances. "'Cannot' Implies 'Not Ought.'” Philosophical Studies 130, no. 2 (August 2006): 233-46.

Prior, Arthur. “Thank Goodness That's Over." Philosophy 34, no. 128 (1959): 12-17. Ripstein, Arthur. Force and Freedom: Kant's Legal and Political Philosophy. Cambridge, MA: Harvard University Press, 2009.

Ryan, Sharon. "Doxastic Compatibilism and the Ethics of Belief." Philosophical Studies 114, nos. 1-2 (May 2003): 47-79.

Saka, Paul. "Ought Does Not Imply Can." American Philosophical Quarterly 37, no. 2 (April 2000): 93-105.

Simmons, A. John. "Original-Acquisition Justifications of Private Property." Social Philosophy and Policy 11, no. 2 (Summer 1994): 63-84.

Sinnott-Armstrong, Walter. “'Ought' Conversationally Implies 'Can.” Philosophical Review 93, no. 2 (April 1984): 249-61.

Stilz, Anna. Liberal Loyalty. Princeton, NJ: Princeton University Press, 2009.

Streumer, Bart. "Reasons and Impossibility." Philosophical Studies 136, no. 3 (December 2007): 351-84.

Talbot, Brian. “The Best Argument for 'Ought Implies Can' Is a Better Argument against 'Ought Implies Can.”' Ergo 3, no. 14 (2016): 377-402.

van der Vossen, Bas. "Imposing Duties and Original Appropriation." Journal of Political Philosophy 23, no. 1 (March 2015): 64-85.

Vranas, Peter B. M. "I Ought, Therefore I Can." Philosophical Studies 136, no. 2 (November 2007): 167-216.

Waldron, Jeremy. "Kant's Legal Positivism." Harvard Law Review 109, no. 7 (1996): 1553-66.

. The Right to Private Property. Oxford: Clarendon Press, 1988.

Waller, Bruce. Against Moral Responsibility. Cambridge, MA: MIT Press, 2011.

Wenar, Leif. "Original Acquisition of Private Property." Mind 107, no. 428 (October 1998): 799-817. 